\title{
An Ab Initio Approach Towards Engineering Fischer- Tropsch Surface Chemistry
}

Type of Report: Technical Progress Report

Report Period: 9/11/2004 - 9/11/2005

Principle Author: Matthew Neurock and David A. Walthall

Date: May 7, 2006

DOE Award Number: DE-FG26-01NT41275

Name and Address of Submitting Organization:

Professor Matthew Neurock

Department of Chemical Engineering

102 Engineers' Way

University of Virginia

Charlottesville, VA 22904-4741 


\section{DISCLAIMER}

This report was prepared as an account of work sponsored by an agency of the United States Government. Neither the United States Government nor any agency thereof, nor any of their employees, makes any warranty, express or implied, or assumes any legal liability or responsibility for the accuracy, completeness, or usefulness of any information, apparatus, product, or process disclosed, or represents that its use would not infringe privately owned rights. Reference herein to any specific commercial product, process, or service by trade name, trademark, manufacturer, or otherwise does not necessarily constitute or imply its endorsement, recommendation, or favoring by the United States Government or any agency thereof. The views and opinions of the authors expressed herein do not necessarily state or reflect those of the United States Government or any agency thereof. 


\section{ABSTRACT}

One of the greatest societal challenges over the next decade is the production of cheap, renewable energy for the 10 billion people that inhabit the earth. This will require the development of various different energy sources potentially including fuels derived from methane, coal, and biomass and alternatives sources such as solar, wind and nuclear energy. One approach will be to synthesize gasoline and other fuels from simpler hydrocarbons such as $\mathrm{CO}$ derived from methane or other U.S. based sources such as coal. Syngas $\left(\mathrm{CO}\right.$ and $\left.\mathrm{H}_{2}\right)$ can be readily converted into higher molecular weight hydrocarbons through Fischer-Tropsch synthesis. Fischer-Trosch synthesis involves the initiation or activation of $\mathrm{CO}$ and $\mathrm{H}_{2}$ bonds, the subsequent propagation steps including hydrogenation and carbon-carbon coupling, followed by chain termination reactions. Commercially viable catalysts include supported Co and Co-alloys. Over the first two years of this project we have used ab initio methods to determine the adsorption energies for all reactants, intermediates, and products along with the overall reaction energies and their corresponding activation barriers over the $\mathrm{Co}(0001)$ surface. Over the third year of the project we developed and advanced an ab initio-based kinetic Monte Carlo simulation code to simulate Fischer Tropsch synthesis.

This report details our work over the last year which has focused on the derivation of kinetic parameters for the elementary steps involved in FT synthesis from ab initio density functional theoretical calculations and the application of the kinetic Monte Carlo algorithm to simulate the initial rates of reaction for FT over the ideal $\mathrm{Co}(0001)$ surface. The results from our simulations over $\mathrm{Co}(0001)$ indicate the importance of stepped surfaces for the activation of adsorbed CO. In addition, they demonstrate that the dominant $\mathrm{CH}_{\mathrm{x}}{ }^{*}$ surface intermediate under steady state conditions is $\mathrm{CH}^{*}$. This strongly suggests that hydrocarbon coupling occurs through reaction with the adsorbed $\mathrm{CH}^{*}$. 


\section{TABLE OF CONTENTS}

DISCLAIMER

2

I. ABSTRACT 3

II. TABLE OF CONTENTS 4

III. INTRODUCTION 5

IV. $\quad$ EXECUTIVE SUMMARY 9

V. COMPUTATIONAL METHODS 11

$\begin{array}{ll}\text { VI. RESULTS AND DISCUSSION } & 13\end{array}$

VII. $\quad$ CONCLUSION AND FUTURE EFFORTS 19

$\begin{array}{ll}\text { VIII. REFERENCES } & 21\end{array}$ 


\section{INTRODUCTION}

Fischer-Tropsch (FT) synthesis involves the catalytic conversion of $\mathrm{CO}$ and $\mathrm{H}_{2}$ into long-chain hydrocarbons, which can be used to produce a variety of different commercially relevant fuels

and products including diesel, heating oil, and higher hydrocarbons. Both Sasol as well as Shell have commercial ventures based on FT synthesis technology. The demand for cheaper more prevalent energy sources have made FT synthesis quite attractive as it can produce very high purity hydrocarbons that can be readily converted into high purity fuels. The products are virtually free of sulfur, nitrogen and metallic contaminants, which makes them much more environmentally friendly.

Despite the tremendous number of studies reported in the literature the mechanism for this reaction and the optimal catalysts are still not very well understood [1-8] Most of these studies have focused on the synthesis and characterization of different catalysts with little emphasis on the mechanism or the elementary kinetics. Advances in current catalyst technology will likely require a more complete understanding of the elementary molecular level transformations involved in FT synthesis along and the atomistic-scale features of the catalyst that control these elementary processes.

The overall Fischer-Tropsch reaction is comprised of a complex network of bond-making and bond-breaking elementary steps, which are highlighted in Figure 1. 


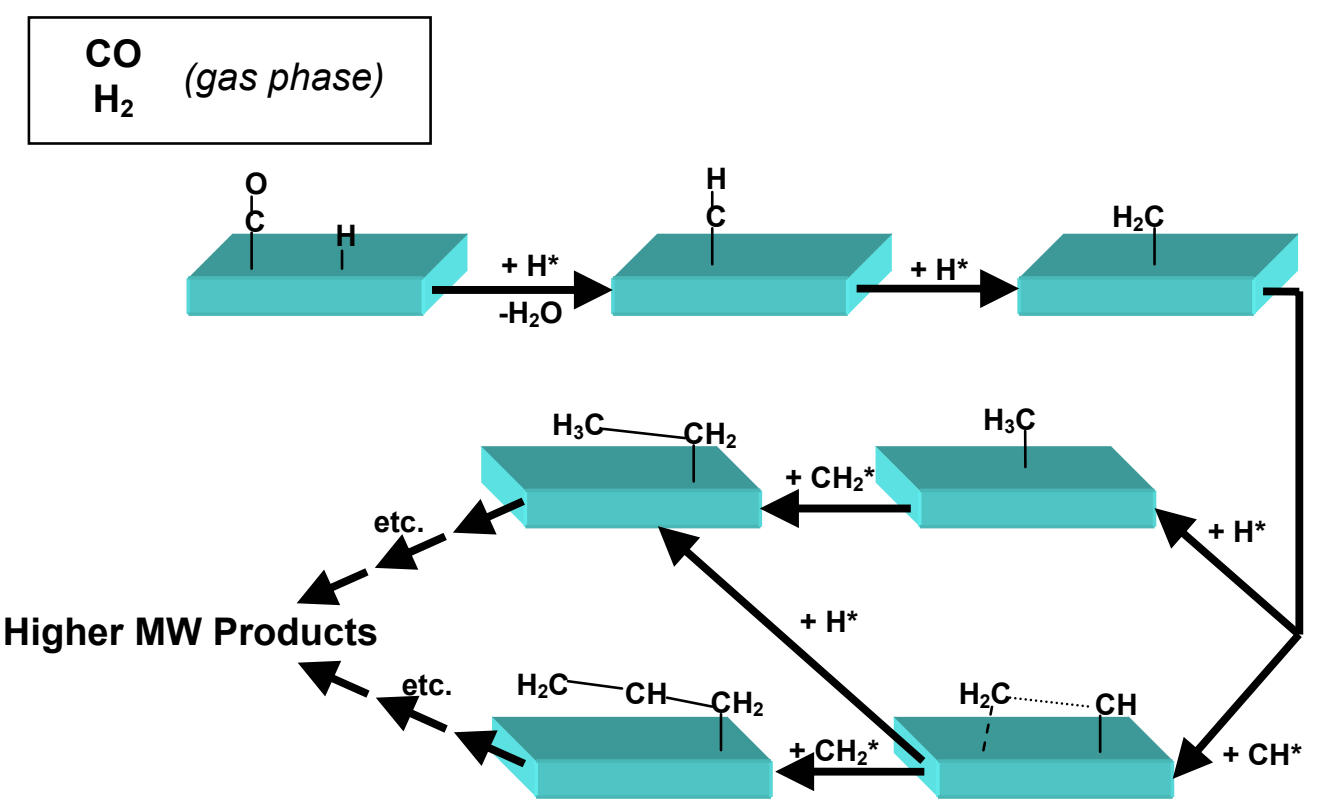

Figure 1. Schematic of some elementary reaction steps in the Fischer-Tropsch synthesis

These include the activation of adsorbed $\mathrm{CO}$ and $\mathrm{H}_{2}$, the hydrogenation of carbon-containing surface intermediates, and carbon-carbon coupling reactions. The balance between the rates of these reactions is what controls the reactivity and selectivity of the process. For example, it is known that transition metals to the left side of the periodic table will readily dissociate adsorbed CO. However, the products, namely surface chemisorbed carbon $\left(\mathrm{C}^{*}\right)$ and oxygen $\left(\mathrm{O}^{*}\right)$ can strongly inhibit the rate of hydrogenation reactions and hydrocarbon coupling reactions. On the other hand, $\mathrm{C}^{*}$ and $\mathrm{O}^{*}$ on the transition metals to the right side of the periodic table can readily undergo hydrogenation and coupling reactions. The barrier to $\mathrm{CO}$ activation, however, is prohibitively high. $[9,10]$ The optimal material should readily dissociate $\mathrm{CO}^{*}$ yet not be poisoned by strongly adsorbed carbon or oxygen. In addition, an ideal catalyst would have the proper balance of hydrogenation and carbon-carbon coupling reactions to promote high molecular weight hydrocarbon products. The products that form under reaction conditions may, to a large extent, be controlled by the species present at the surface as the reaction proceeds. 
Various speculations as to the dominant surface intermediate have been proposed but there are no clear in-situ or operondo spectroscopic data or firm theoretical predictions on what the nature of the surface is as a function of time or reaction conditions.

In the first two years of this grant, we have examined several key elementary steps over different catalyst surfaces. Ab initio density functional theoretical calculations were carried out to determine the activation barriers for $\mathrm{CO}^{*}$ dissociation over $\mathrm{Co}(0001)$ surfaces. We examined in some detail the adsorption of $\mathrm{CO}$ at various different sites on different surfaces including $\operatorname{Co}(10 \overline{1} 2), \operatorname{Co}(11 \overline{2} 0)$ and $\operatorname{Co}(11 \overline{2} 4)$ in order to elucidate the role of step defect sites on $\mathrm{CO}$ activation. In addition, we calculated the overall reaction and activation energies for a number of different carbon-carbon coupling reactions over the model $\mathrm{Co}(0001)$ and $\mathrm{Ru}(0001)$ surfaces. We also examined the binding energies and hydrogenation reactions of $\mathrm{CH}_{\mathrm{x}}$ over the model $\mathrm{Co}(0001), \operatorname{Pt}(111)$ and $\mathrm{Ru}(0001)$ surfaces. In addition, we explored the effect of surface coverage of $\mathrm{C}^{*}$ on the individual hydrogenation reactions.

In the third year we developed a general kinetic Monte Carlo method to simulate FT synthesis over model Co surfaces. In the past year, we have focused on understanding the relationship and the kinetics between the elementary reactions on the model surface of $\mathrm{Co}(0001)$ to better understand the mechanism of the Fischer-Tropsch reaction at an atomic level. We have completed the kinetic Monte Carlo (started in year 3) to simulate the molecular transformations of individual molecule for FT, and their behavior as a function of time as well as reaction conditions. We used the binding energies and reaction barriers from our DFT calculations as the input to the kinetic Monte Carlo simulations. We analyzed the surface coverage of the $\mathrm{CH}_{\mathrm{x}}$ 
species as a function of time in the absence of carbon-carbon coupling reactions. Finally we have started to include some of the carbon-carbon coupling reactions to better understand the chain growth mechanism. 


\section{EXECUTIVE SUMMARY}

In recent years, there has been an increased interest in the Fischer-Tropsch synthesis as an alternative source of liquid hydrocarbon fuels from sources such as methane and coal. Fischer-Tropsch synthesis involves a complex set of bond breaking and bond making reactions. The balance between these steps dictates the ultimate product distribution. These reactions include the activation of $\mathrm{CO}$ and $\mathrm{H}_{2}$, the hydrogenation of hydrocarbon surface intermediates, the coupling of hydrocarbon intermediates, and the desorption of products. A key aspect of Fischer-Tropsch catalysts is that they must promote $\mathrm{CO}$ activation. In addition, a careful balance of surface species hydrogenation reactions and hydrocarbon coupling reactions is crucial to produce longer chain hydrocarbon products. While this reaction has been studied for many years, there is still a rather poor fundamental understanding of how the atomic surface structure influences catalytic performance.

Fischer-Tropsch synthesis involves the activation of $\mathrm{CO}$ and hydrogen, the hydrogenation of different $\mathrm{CH}_{\mathrm{x}}$ intermediates, the coupling of different $\mathrm{CH}_{\mathrm{x}}$ intermediates and finally the termination of the growing hydrocarbon chain. Ultimately, the products that form desorb from the surface. There is a delicate balance between the hydrogenation reactions, carbon-carbon coupling reactions, and desorption reactions that determines the size and composition of the molecular product distribution. In order to examine this system in detail, we have used ab initio quantum mechanical calculations to determine the kinetics for elementary steps and kinetic Monte Carlo simulation to track the changes in the surface and product distribution to changes in the surface structure as well as changes in the operating conditions.

Density functional theoretical calculations were performed to determine the binding energies for various different intermediates at different sites on idealized Co substrates such Co(0001), and calculate overall reaction energies and activation barriers. We have studied in detail the activation of $\mathrm{CO}$ over $\mathrm{Co}(0001)$ and stepped $\mathrm{Co}$ surfaces to better understand the role of surface corrugation and openness on the energetics. In addition, we examined the effect of different coverages on the calculated reaction energies, and we found that both the surface structure and the coverage have significant effects on the energetics.

We have also examined the reaction energies and activation barriers for the hydrogenation of different $\mathrm{CH}_{\mathrm{x}}$ intermediates over $\mathrm{Ru}, \mathrm{Co}$, and $\mathrm{Pt}$ closed packed surfaces to establish periodic trends. The barriers for hydrogenation are higher for metals that lie to the left in the periodic table due to the difficulty associated with breaking the metal-carbon and metal-hydrogen bonds. These calculations were also carried out at different coverages in order to establish the influence of the interaction of intermediates that takes place at the higher coverages. Our studies of the hydrocarbon coupling reactions over $\mathrm{Co}(0001)$ suggest that both $\mathrm{CH}_{2}$ and $\mathrm{CH}$ may be kinetically important intermediates.

Over this past year, we have developed a kinetic Monte Carlo algorithm to simulate the initial kinetics involved in Fischer-Tropsch synthesis over $\mathrm{Co}(0001)$ as well as other ideal surfaces. Kinetic Monte Carlo simulations begin to provide a link between the idealized theoretical calculations which are typically carried out at low surface coverage conditions and more realistic operating conditions by embedding models that describe the nature of lateral interactions 
between coadsorbed molecules that take place at higher coverages and are the result of more realistic higher pressures conditions. The simulations can thus be used to carry out "virtual experiments" to probe the sensitivity of different reactions and or kinetics to the resulting catalytic performance. In addition, they can be used to provide insight into the relative importance of different reaction pathways. This can be performed by turning on and off specific reactions or adjusting their calculated rate constants. This also provides insight into the governing reaction mechanisms.

The results from the simulations indicate that $\mathrm{CO}$ does not dissociate on the terrace sites of the $\mathrm{Co}(0001)$ surface under typical operating conditions. $\mathrm{CO}$ ultimately blocks the surface and begins to drive hydrogen off of the surface. CO activation, however, is much more prevalent at step sites as was suggested by the DFT results. The KMC simulations that use the barriers for $\mathrm{CO}$ dissociation at step sites show that the dissociation of $\mathrm{CO}$ happens on the time scales which are on the order of other reaction steps. The simulation results indicate that there is an initial build-up of hydrogen on the surface since $\mathrm{H}_{2}$ has a much lower barrier for activation than $\mathrm{CO}$. At longer times, however, some of the hydrogen is still driven off the surface by $\mathrm{CO}^{*}, \mathrm{C}^{*}$, and $\mathrm{O}^{*}$. As the surface concentration of $\mathrm{CO}^{*}$ continues to rise, most of the $\mathrm{O}^{*}$ reacts with $\mathrm{CO}^{*}$ and desorbs from the surface as $\mathrm{CO}_{2}(\mathrm{~g})$. A fraction of the adsorbed oxygen atoms react to form hydroxides or water (which desorbs). This suggests that our hydrogenation rates maybe too slow or that $\mathrm{CO}$ activation should occur at even higher rates since water should be the primary oxygenated product. At steady state, the surface concentration of $\mathrm{CO}$ reaches a coverage of $0.45 \mathrm{ML}$. The surface coverage of $\mathrm{CH}^{*}$ at steady-state reaches a value of $0.12 \mathrm{ML}$. Small amounts of $\mathrm{CH}_{2} *$ are also present on the surface. The hydrogenation of $\mathrm{CH}_{2} *$ to $\mathrm{CH}_{3} *$ is more difficult. In addition, any $\mathrm{CH}_{3}$ * that forms readily dehydrogenate back to $\mathrm{CH}_{2}{ }^{*}$ and $\mathrm{H}^{*}$. The dominant carbon-carbon coupling reactions then are $\mathrm{CH}^{*}+\mathrm{CH}^{*}$ or $\mathrm{CH}^{*}+\mathrm{CH}_{2} *$. 


\section{COMPUTATIONAL METHODS}

All of the ab initio calculations reported herein were carried out using gradient-corrected plane-wave density functional theoretical methods as implemented in the Vienna ab initio Simulation Package (VASP) developed by Kresse and coworkers.[11-15] Ultra-soft pseudopotentials with a plane-wave cutoff energy of $287 \mathrm{eV}$ were used for all of the calculations.[16] The Perdew-Wang (PW91) form of the generalized gradient approximation was used to calculate the exchange and correlation energies.[17] Surfaces were modeled using 2x2 supercells with four metal atom layers, and the Monkhorst-Pack mesh was used to sample the first Brillouin zone.[18] Transition states were located using the Nudged Elastic Band technique as implemented in VASP.[19]

The kinetic Monte Carlo simulations were carried out using the basic algorithms developed for this project last year and in addition previous models and subroutines developed earlier [20]. The current algorithm uses a variable-time approach that simulates the temporal changes of the adsorbate layer, using a surface with periodic boundary conditions. A fairly comprehensive database was constructed from DFT-calculated binding energies for $\mathrm{H}, \mathrm{O}, \mathrm{C}, \mathrm{CH}, \mathrm{CH}_{2}, \mathrm{CH}_{3}$, $\mathrm{CH}_{4}$ and $\mathrm{C}_{2} \mathrm{H}_{\mathrm{x}}$ intermediates, and overall reaction and activation energies for $\mathrm{CO}$ and $\mathrm{H}_{2}$ activation, $\mathrm{CH}_{\mathrm{x}}$ hydrogenation, and $\mathrm{CH}_{\mathrm{x}}$ coupling reactions. This resulting database is considered the zero-coverage limit for the reactions considered. Lateral interactions, defined as either through-surface or through space, were modeled by using more coarse-grained models. Through-surface interactions are described as changes in the adsorption energies and reaction energies that arise from electronic interactions that take place through the metal surface as the result of coadsorption. We have shown previously that these interactions strongly depend on the 
number of metal atoms in the adsorption complex that have bonds to other adsorbates. They can be weakly attractive for cases where adsorbate do not share metal atoms but remain nearby or highly repulsive for adsorbates which share one or more metal atoms. These interactions typically follow the bond order conservation principles. Bond Order Conservation (BOC) methods therefore have proven to be quite useful for modeling through-surface interactions.[2124] Through-space interactions are those that occur through space. These are typically steric type interactions that can be modeled by the inclusion of the electrostatic and van der Waals interactions. We have shown that these interactions can be modeled reasonably well by using force field models. We have successfully used the Merck Molecular Force Field (MMFF94) in previous studies and therefore this approach is adopted herein.[25, 26] Both the BOC algorithm as well as the MMFF algorithm can be called upon internal within the simulation to explicitly account for the effects of the local surface coverage.

For each time step, the barriers for all possible adsorption, desorption and surface reactions are computed. Using an Arrhenius relationship, the rate for each possible reaction can be calculated. The next reaction to occur in the system is chosen by comparing a randomly chosen number with a cumulative probability distribution for all of the possible events. The probability of choosing a specific reaction is proportional to its rate reaction verses the overall rate which is taken as the sum of the rates for all events at that particular instant in time. The time is advanced by choosing a second random number, and is inversely proportional to the total rate calculated, so that surfaces with larger total rates of reactions will be incremented by smaller time steps than surfaces with smaller total rates of reactions. The simulations follow a hybrid variable-time step and fixed-time step approach. The reactions are ascribed to variable time steps. A number of 
fixed time steps are subsequently carried out between each successive variable time step in order to simulate diffusion. This approach enables us to simulate both reaction events together with diffusion events without having to resort to neglecting diffusion or assuming that the reaction is fully equilibrated.

\section{RESULTS AND DISCUSSION}

Fischer-Tropsch synthesis can be viewed as three separate sets of reactions: initiation, propagation, and termination. The initiation reactions consist of the adsorption of gas phase $\mathrm{CO}$ and $\mathrm{H}_{2}$ and their subsequent dissociation to generate the hydrocarbon precursors, $\mathrm{C}^{*}, \mathrm{O}^{*}$ and $\mathrm{H}^{*}$. The second set of reactions are referred to as the propagation reactions. They consist of hydrogenation reactions and carbon-carbon coupling reactions. In the hydrogenation reactions, surface hydrocarbons react with surface hydrogen atoms $\left(\mathrm{C}_{\mathrm{x}} \mathrm{H}_{\mathrm{y}}{ }^{*}+\mathrm{H}^{*} \rightarrow \mathrm{C}_{\mathrm{x}} \mathrm{H}_{\mathrm{y}+1}{ }^{*}\right)$. In the carbon-carbon coupling reactions, two surface hydrocarbon species react to form a larger surface hydrocarbon species $\left(\mathrm{C}_{\mathrm{x}} \mathrm{H}_{\mathrm{y}} *+\mathrm{C}_{\mathrm{a}} \mathrm{H}_{\mathrm{b}} * \rightarrow \mathrm{C}_{\mathrm{x}+\mathrm{a}} \mathrm{H}_{\mathrm{y}+\mathrm{b}}{ }^{*}\right)$. The carbon-carbon coupling reactions are therefore chain growth reactions which increase the size and molecular weight of the surface intermediates. The hydrogenation reactions and the coupling reactions can produce either strongly adsorbed radical-like intermediate hydrocarbons or result in the formation of more weakly bound closed-shell hydrocarbon products. The later process is typically referred to as termination. The close-shell species can desorb from the surface. The balance between all of these reactions is what determines the product distribution. 


\section{Initiation Reactions}

We have previously calculated the barrier to dissociate $\mathrm{CO}^{*}$ on the model $\mathrm{Co}(0001)$ surface at $140 \mathrm{~kJ} / \mathrm{mol}$ for a $1 / 9 \mathrm{ML}$ coverage. The barrier rises significantly to about $230 \mathrm{~kJ} / \mathrm{mol}$ for a 1/4 ML coverage. Using this barrier for dissociation, the simulations showed essentially no dissociation of adsorbed $\mathrm{CO}$ at realistic operating conditions. The increased barrier is the result of lateral repulsive surface interactions together with a lack of availability of sites.

In addition to $\mathrm{CO}^{*}$ dissociation barriers over the $\mathrm{Co}(0001)$ surface, we have also calculated the dissociation barrier over the model stepped surfaces including the $\operatorname{Co}(10 \overline{1} 2), \operatorname{Co}(11 \overline{2} 0)$, and $\operatorname{Co}(11 \overline{2} 4)$ surfaces shown in Figure 2. On the $\operatorname{Co}(10 \overline{1} 2)$ surface the dissociation of CO* was calculated to be exothermic. This same reaction, however, was calculated to be endothermic on the other three surfaces examined (including the $\mathrm{Co}(0001)$ surface). In addition, the $\mathrm{CO}^{*}$ activation barrier $(110 \mathrm{~kJ} / \mathrm{mol})$ over the $\operatorname{Co}(10 \overline{1} 2)$ surface is also significantly smaller than those of the other four surfaces. By using this barrier in the simulations, the coverage of $\mathrm{CO}^{*}$ drops from about $0.5 \mathrm{ML}$ to about $0.4 \mathrm{ML}$. More significantly, the dissociation of $\mathrm{CO}^{*}$ becomes quite facile, and $\mathrm{CO}^{*}, \mathrm{C}^{*}$, and $\mathrm{O}^{*}$ are all present on the surface. From this, we conclude that surface corrugation (i.e. steps or kinks) is essential for $\mathrm{CO}^{*}$ dissociation to take place in quantities sufficient to generate products to any appreciable degree. In addition, because the dissociation of $\mathrm{CO}^{*}$ over the stepped surfaces is so much faster than $\mathrm{CO}^{*}$ dissociation over the $\mathrm{Co}(0001)$ surface, it is likely that only a small fraction of the total surface needs to be the steps in order for there to be a sufficient quantity of $C^{*}$ present on the surface. 


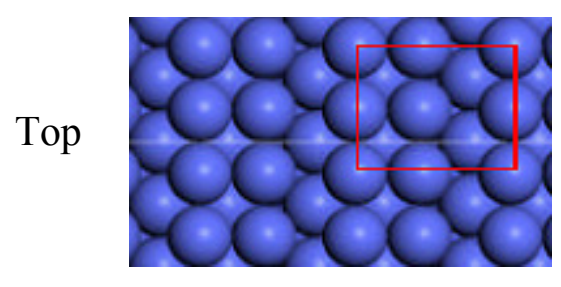

Side

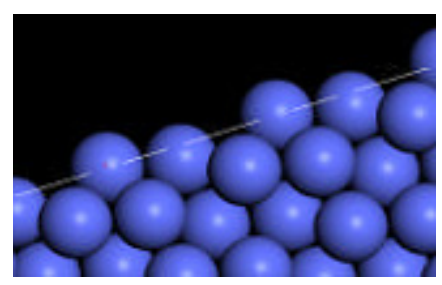

$\operatorname{Co}(10 \overline{1} 2)$
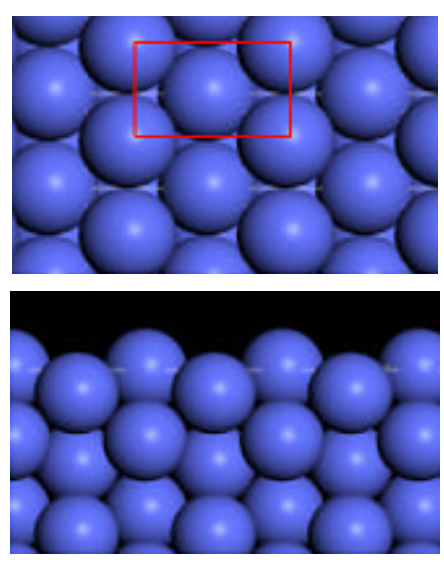

$\operatorname{Co}(11 \overline{2} 0)$
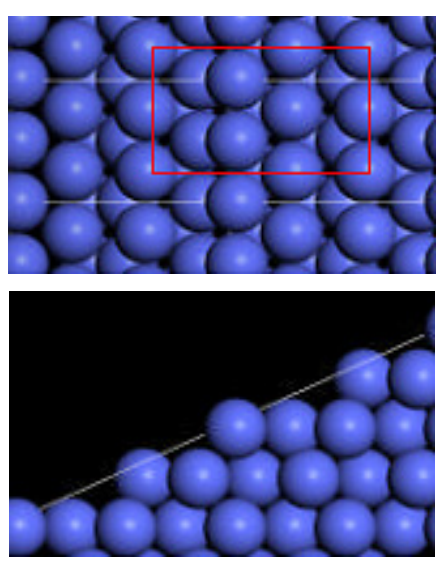

$\operatorname{Co}(11 \overline{2} 4)$

Figure 2. Top and side view of the Co surfaces. The red box is the minimum unit cell size.

The dissociative adsorption of $\mathrm{H}_{2}(\mathrm{~g})$ was set to have a barrier of $40 \mathrm{~kJ} / \mathrm{mol}$ in order simply test the code. This reaction is typically very fast so that even at these relatively high barriers, the reaction occurs frequently enough that $\mathrm{H}^{*}$ is in equilibrium with gas phase $\mathrm{H}_{2}$.

The DFT barriers and overall energies were collectively used with lateral interaction models to simulate various different initial kinetics. The initial simulations of $\mathrm{CO}$ and $\mathrm{H}_{2}$ activation show that there is a fast build-up of $\mathrm{H}^{*}$ in about the first $10^{-8}$ of a second to establish a surface coverage of about $0.1 \mathrm{ML}$. CO then begins to dissociate. The $\mathrm{C}^{*}, \mathrm{O}^{*}$ and initial $\left(\mathrm{CH}^{*}\right)$ hydrogenation products begin to appear and drive adsorbed hydrogen from the surface. The surface coverage of $\mathrm{H}^{*}$ drops down to about $0.02 \mathrm{ML}$, where it stays fairly constant for the rest of the simulation. The surface $\mathrm{O}^{*}$ also goes through an initial build-up period. The surface coverage of $\mathrm{O}^{*}$ peaks at about $10^{-7}$ seconds at a value of about $0.1 \mathrm{ML}$. It then begins a steady decline towards it steady-state value of $0.02 \mathrm{ML}$, which it reaches by about $10^{-6}$ seconds. 


\section{Propagation Reactions: Hydrogenation Reactions}

The hydrogenation reactions over the model Co(0001) surface were calculated using VASP. The hydrogenation reaction energies and reaction barriers for $\mathrm{CH}_{\mathrm{x}}{ }^{*}$ are shown in Figure 3. From the figure, it is clear that the energetically most favorable surface species is $\mathrm{CH}^{*}$. At equilibrium, we would therefore expect to have surface coverages in the following order:

$$
\mathrm{CH}^{*}>\mathrm{CH}_{3}^{*}>\mathrm{CH}_{2} * \mathrm{C}^{*} \text {. }
$$

The formation of $\mathrm{CH}_{4}(\mathrm{~g})$ is also energetically favorable as it compares with the energy to form $\mathrm{CH}_{3} *$.

\section{Activation Barriers and Adsorption Energies on Co(0001)}

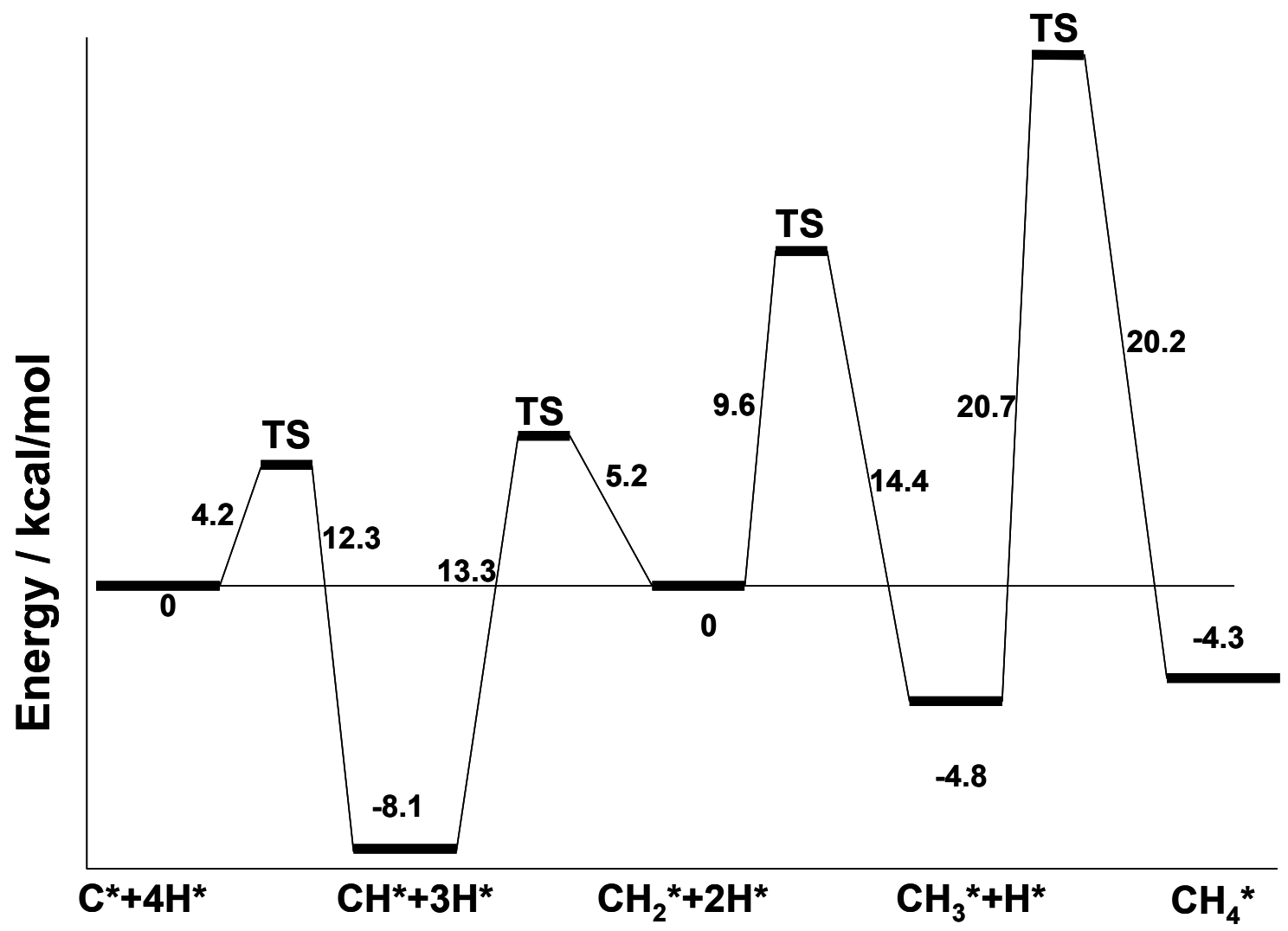

Figure 3. The hydrogenation of $\mathrm{CH}_{\mathrm{x}}{ }^{*}$ intermediates over $\mathrm{Co}(0001)$. 
The kinetic Monte Carlo simulations which include the hydrogenation reactions reveal interesting results. After the surface coverage of $\mathrm{H}^{*}$ begins to decrease (starting at about $10^{-8}$ seconds), $\mathrm{CH}^{*}$ becomes the dominant species (rather than $\left.\mathrm{CO}^{*}\right) . \mathrm{CH}^{*}$ reaches a surface coverage of a little less than $0.1 \mathrm{ML}$ by $10^{-7}$ seconds, which is the time that $\mathrm{H}^{*}$ has predominantly disappeared from the surface. Figure 4 shows surface coverages of the most abundant surface species.

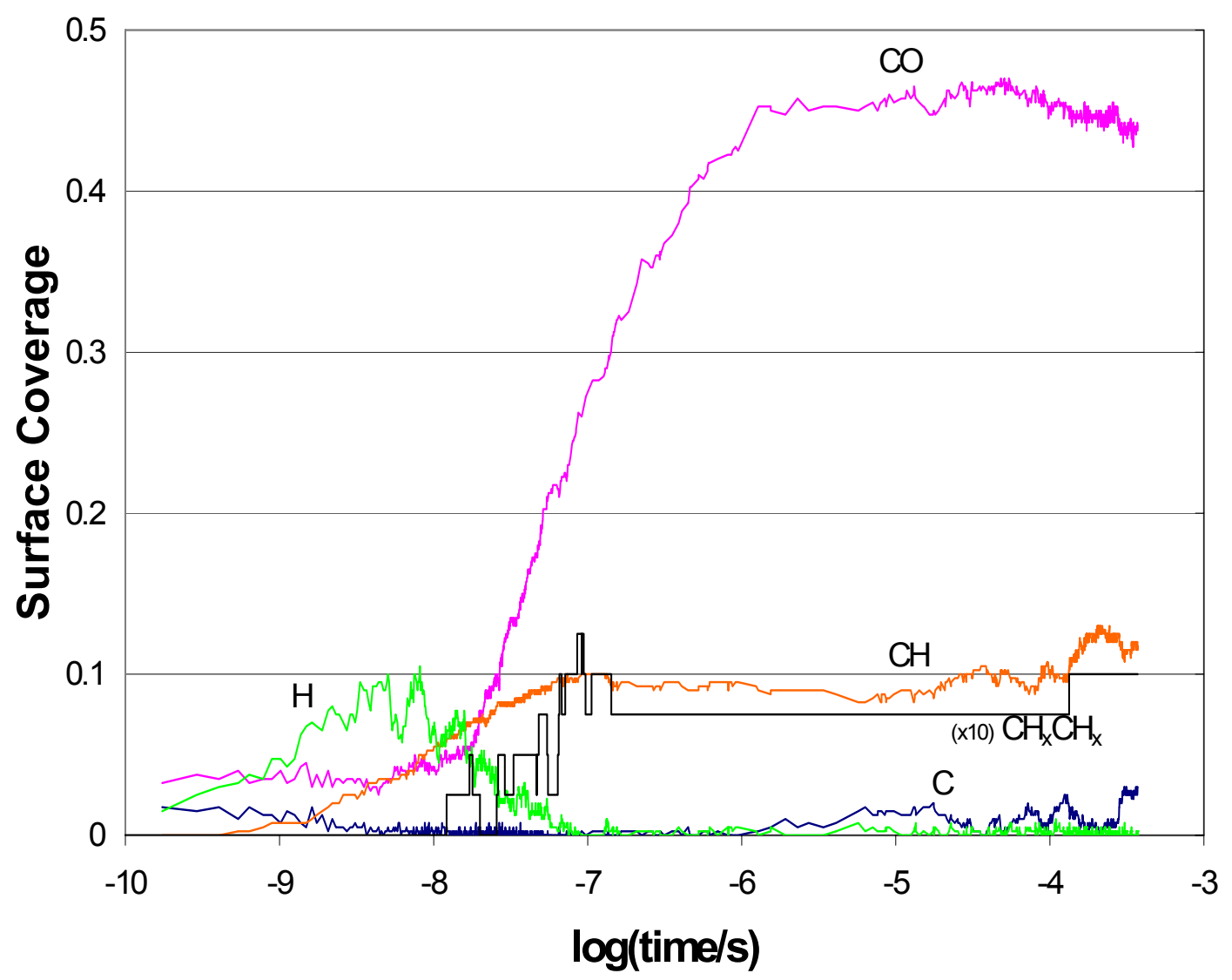

Figure 4. Kinetic Monte Carlo Surface Coverages. 
Unlike what would be predicted from the pure thermodynamic reaction energies, $\mathrm{CH}_{3} *$ is not the next most abundant $\mathrm{CH}_{\mathrm{x}}{ }^{*}$ species on the surface. The simulations demonstrate that $\mathrm{CH}^{*}$ is the most abundant $\mathrm{CH}_{\mathrm{x}}$ surface intermediate. The coverages of $\mathrm{C}^{*}$ and $\mathrm{CH}_{2} *$ follow that of $\mathrm{CH}^{*}$ but only have surface coverage of about $0.005 \mathrm{ML}$ and $0.02 \mathrm{ML}$ respectively. This can be understood from the kinetics of the hydrogenation reactions, seen in Figure 3. There is only a small barrier to hydrogenate $\mathrm{C}^{*}$ to form $\mathrm{CH}^{*}$. The barrier to hydrogenate $\mathrm{CH}^{*}$ to form $\mathrm{CH}_{2} *$ is roughly the same as the barrier to dehydrogenate $\mathrm{CH}^{*}$ to form $\mathrm{C}^{*}$ and $\mathrm{H}^{*}$. Thus, it is not too surprising to find that those two species are present in small amounts and at a lower surface coverage than $\mathrm{CH}^{*}$.

The barrier to form $\mathrm{CH}_{3} *$ from $\mathrm{CH}_{2} *$ and $\mathrm{H} *$ is roughly similar to the barrier to form $\mathrm{CH}_{2} *$ from $\mathrm{CH}^{*}$ and $\mathrm{H}^{*}$. However, because the surface coverage of $\mathrm{CH}_{2} *$ is significantly lower than the coverage of $\mathrm{CH}^{*}$, we find that the surface coverage of $\mathrm{CH}_{3} *$ is much smaller. The rates of course are controlled not only by the barriers but by the surface coverages. Finally, the barrier to form $\mathrm{CH}_{4}$ from $\mathrm{CH}_{3} *$ and $\mathrm{H}^{*}$ is significantly higher than the other hydrogenation barriers. The high barriers, combined with the lower surface coverage of $\mathrm{CH}_{3} *$ ultimately results in the lack of production of $\mathrm{CH}_{4}$ in the simulations.

\section{Propagation Reactions: Carbon-Carbon Coupling Reactions}

We have calculated the carbon-carbon coupling reaction energies and reaction barriers from $a b$ initio Density Functional Theory calculations. We found that the barrier for the reaction of $\mathrm{CH}_{2} *+\mathrm{CH}_{2} *$ to form $\mathrm{CH}_{2} \mathrm{CH}_{2} *$ is $7.2 \mathrm{~kJ} / \mathrm{mol}$. The barrier for the reaction of $\mathrm{CH}^{*}+\mathrm{CH}_{2} *$ to form $\mathrm{CHCH}_{2} *$ is significantly higher at $55.9 \mathrm{~kJ} / \mathrm{mol}$. This is due to the fact that the $\mathrm{CH}^{*}$ group is 
much more strongly bound to the surface than the $\mathrm{CH}_{2}$ * group. We have not yet included any coupling reactions to form $\mathrm{C}_{3}+\mathrm{H}_{\mathrm{x}}{ }^{*}$ species in the simulations as we first wanted to establish the initial $\mathrm{C}_{2} \mathrm{H}_{\mathrm{x}}$ formation paths.

Kinetic Monte Carlo simulations of the system shows that some $\mathrm{C}_{2} \mathrm{H}_{\mathrm{x}}{ }^{*}$ species is formed on the surface. Although we did not calculate the barrier for the reaction of $\mathrm{CH}^{*}+\mathrm{CH}_{3} *$ to form $\mathrm{CHCH}_{3}{ }^{*}$, bond order conservation estimated that reaction barrier to be around $46 \mathrm{~kJ} / \mathrm{mol}$. In addition, the coverage effects changed the $\mathrm{CH}^{*}+\mathrm{CH}_{2} *$ reaction barrier to be $50-300 \mathrm{~kJ} / \mathrm{mol}$, depending on the local coverage. The reactions of $\mathrm{CH}^{*}+\mathrm{CH}_{2} *$ and $\mathrm{CH}^{*}+\mathrm{CH}_{3} *$ were the only carbon-carbon coupling reactions seen. In fact, the $\mathrm{CH}_{2}{ }^{*}$ coverage was low enough that $\mathrm{CH}_{2} *+\mathrm{CH}_{2} *$ was not even a common possible reaction. Once $\mathrm{C}_{2} \mathrm{H}_{\mathrm{x}}$ * species were formed, they typically underwent hydrogenation reaction and dehydrogenation reactions to lead to the formation of chain terminating products. Some underwent decoupling reactions to form $\mathrm{CH}_{\mathrm{x}}{ }^{*}+\mathrm{CH}_{\mathrm{y}} *$ species, although this was less common. This will be an area of focus over the next year or two.

\section{CONCLUSION AND FUTURE EFFORTS}

We have completed an ab initio-based kinetic Monte Carlo algorithm developed in the previous year and applied it to simulate kinetics of the initial catalytic reaction paths for Fischer-Tropsch synthesis over model Co(0001) substrates. The results from ab initio Density Functional Theoretical calculations carried out in this grant were used within these kinetic Monte Carlo simulations to show that $\mathrm{CO}^{*}$ dissociation on the $\mathrm{Co}(0001)$ surface is too large to produce the required surface coverages of $\mathrm{C}^{*}$ for Fischer-Tropsch to occur. The dissociation of $\mathrm{CO}$ over the 
stepped surface was found to have a much lower barrier, and thus occurring at time scales such as those reported in the literature. This step edges or defect sites are responsible for activating $\mathrm{CO}$ to produce surface carbon. However, the number of steps can be a small fraction of the total surface. Initial simulations indicate that the dominant surface intermediate is $\mathrm{CH}^{*}$, although small amounts of $\mathrm{CH}_{2} *$ and very small amounts of $\mathrm{CH}_{3} *$ are present. The surface coverage of $\mathrm{CH}_{2} *$ is so low, however, that the $\mathrm{CH}_{2} *+\mathrm{CH}_{2} *$ reaction is seldom possible in the simulations and that chain coupling appears to proceed through the reaction of the most abundant $\mathrm{CH}^{*}$ intermediate on the surface.

Future efforts will include further calculations on the carbon-carbon coupling reaction barriers so that we can simulate more of the chain growth on the ideal (0001) terraces as well as at stepped defect sites. We will include $\mathrm{C}_{3+} \mathrm{H}_{\mathrm{x}}$ * species in the kinetic Monte Carlo simulations in order to examine coupling to form higher hydrocarbons. In addition, we have previously calculated some of the binding energies and reaction barriers on $\operatorname{Pt}(111)$ and $\mathrm{Ru}(0001)$ surfaces, which will allow us to investigate alloys using our Monte Carlo code. 


\section{REFERENCES}

1. Fischer, F. and H. Tropsch, Preparation of Synthetic Oil Mixtures (Synthol) From Carbon Monoxide and Hydrogen. I. Brennstoff-Chem., 1923. 4: p. 276-285.

2. Fischer, F. and H. Tropsch, Preparation of Synthetic Oil (Synthol) From Carbon Monoxide and Hydrogen. II. Brennstoff-Chem., 1924. 5: p. 201-208.

3. Anderson, R.B., The Fischer-Tropsch Synthesis. 1984, New York: Academic Press.

4. Iglesia, E., S.C. Reyes, R.J. Madon, and S.L. Soled, Selectivity Control and Catalyst Design in the Fischer-Tropsch Synthesis - Sites, Pellets, and Reactors. Advances in Catalysis, 1993. 39: p. 221-302.

5. Iglesia, E., Design, Synthesis, and Use of Cobalt-based Fischer-Tropsch Synthesis Catalysts. Applied Catalysis A, 1997. 161(1-2): p. 59-78.

6. Thomas, J.M. and W.J. Thomas, Principles and Practices of Heterogeneous Catalysis. 1997, Weinheim: VCH Publishing Company.

7. van der Laan, G.P., A.A.C.M. Beenackers, and R. Krishna, Multicomponent reaction engineering model for Fe-catalyzed Fischer-Tropsch synthesis in commercial scale slurry bubble column reactors. Chemical Engineering Science, 1999. 54(21): p. 50135019.

8. Dry, M.E., The Fischer-Tropsch process: 1950-2000. Catalysis Today, 2002. 71(3-4): p. 227-241.

9. Horn, K., A. Bradshaw, and K. Jacobi, Angular-resolved UV photoemission from ordered layers of CO on a Ni(100) surface. Surface Science, 1978. 72: p. 719-732.

10. Vannice, M.A., Catalysis: Science and Technology. Vol. 3. 1982, Berlin: SpringerVerlag.

11. Payne, M.C., M.P. Teter, D.C. Allan, T.A. Arias, and J.D. Joannopoulos, Iterative Minimization Techniques for Abinitio Total-Energy Calculations - Molecular-Dynamics and Conjugate Gradients. Reviews of Modern Physics, 1992. 64(4): p. 1045-1097.

12. Kresse, G. and J. Hafner, Abinitio Molecular-Dynamics for Liquid-Metals. Physical Review B, 1993. 47(1): p. 558-561.

13. Kresse, G. and J. Hafner, Ab-Initio Molecular-Dynamics Simulation of the Liquid-Metal Amorphous-Semiconductor Transition in Germanium. Physical Review B, 1994. 49(20): p. 14251-14269.

14. Kresse, G. and J. Furthmuller, Efficient iterative schemes for ab initio total-energy calculations using a plane-wave basis set. Physical Review B, 1996. 54(16): p. 1116911186.

15. Kresse, G. and J. Furthmuller, Efficiency of ab-initio total energy calculations for metals and semiconductors using a plane-wave basis set. Computational Materials Science, 1996. 6(1): p. 15-50.

16. Vanderbilt, D., Soft Self-Consistent Pseudopotentials in a Generalized Eigenvalue Formalism. Physical Review B, 1990. 41(11): p. 7892-7895.

17. Perdew, J.P., J.A. Chevary, S.H. Vosko, K.A. Jackson, M.R. Pederson, D.J. Singh, and C. Fiolhais, Atoms, Molecules, Solids, and Surfaces - Applications of the Generalized Gradient Approximation for Exchange and Correlation. Physical Review B, 1992. 46(11): p. 6671-6687.

18. Monkhorst, H.J. and J.D. Pack, Special points for Brillouin-zone integrations. Physical Review B, 1976. 13(12-15): p. 5188-5192. 
19. Mills, G., H. Jonsson, and G.K. Schenter, Reversible Work Transition-State Theory Application to Dissociative Adsorption of Hydrogen. Surface Science, 1995. 324(2-3): p. 305-337.

20. Neurock, M. and E.W. Hansen, First-principles-based molecular simulation of heterogeneous catalytic surface chemistry. Computers \& Chemical Engineering, 1998. 22: p. S1045-S1060.

21. Shustorovich, E., Coverage Effects under Atomic Chemisorption - Morse-Potential Modeling Based on Bond-Order Conservation. Surface Science, 1985. 163(1): p. L645L654.

22. Shustorovich, E. and A.T. Bell, An Analysis of Fischer-Tropsch Synthesis by the BondOrder-Conservation-Morse-Potential Approach. Surface Science, 1991. 248(3): p. 359368.

23. Shustorovich, E., Metal Effects in the Fischer-Tropsch Synthesis - Bond-OrderConservation-Morse-Potential Approach. Catalysis Letters, 1991. 7(1-4): p. 107-118.

24. Sellers, H., Relationship among Force-Constants Implied by the Principle of Bond-Order Conservation in Chemisorbed Systems. Journal of Physical Chemistry, 1994. 98(3): p. 968-971.

25. Halgren, T.A., Merck molecular force field .1. Basis, form, scope, parameterization, and performance of MMFF94. Journal of Computational Chemistry, 1996. 17(5-6): p. 490519.

26. Halgren, T.A., Merck molecular force field .2. MMFF94 van der Waals and electrostatic parameters for intermolecular interactions. Journal of Computational Chemistry, 1996. 17(5-6): p. 520-552. 